\title{
Ventilator Shortages and Solutions, Real and Imagined
}

Severe acute respiratory syndrome coronavirus 2 (SARS CoV-2) and resulting corona virus disease 2019 (COVID19) have unfortunately brought to fruition the fears of disaster medicine planners in the form of SARS CoV-1-like severe lung injury that is easily transmitted from person to person. ${ }^{1}$ Since the original description in Wuhan, China, in the winter of 2019, SARS CoV-2 has resulted in surges of critically ill patients overwhelming health systems around the world. ${ }^{2}$ Shortages of personal protective equipment, ventilators, hospital beds, ICU capacity, oxygen, medications, and, perhaps most importantly, staff have been widely reported. ${ }^{3}$ The surge of patients on the east and west coasts of the United States in the spring of 2020 has given way to a steadily rising tide throughout the nation in early 2021. Health systems are facing crisis conditions.

COVID-19 has also made the mechanical ventilator a household term as the surge in the northeast United States during the spring of 2020 focused heavily on ventilator shortages and predictions of future needs exceeding 100,000 ventilators above the existing supply. ${ }^{4,5}$ These predictions stimulated the previous government administration to activate the Defense Production Act, spurring automobile manufacturers to facilitate the mass production of ventilators. ${ }^{6}$

In a recent publication by the multi-society Task Force for Mass Critical Care, an analysis of these purchases, the predicted needs, and the performance characteristics of purchased ventilators were addressed. ${ }^{7}$ The authors highlighted a number of important issues and noted findings related to ventilator allocations from the Strategic National Stockpile. These included describing the importance of predicting the ventilator needs on the basis of the number of patients concurrently requiring mechanical ventilation on a single day, as opposed to the cumulative number of patients requiring ventilation throughout the pandemic. Additionally, the delivery of ventilators from the Strategic National Stockpile to the northeast United States (ie, New York, New Jersey, and Massachusetts), along with improved treatment of COVID19 , prevented ventilator shortages and concerns of ventilator rationing. In short, ventilators from the Strategic National

\footnotetext{
The authors have disclosed no conflicts of interest.

Correspondence: Richard D Branson MSc RRT FAARC, University of Cincinnati, 231 Albert Sabin Way, ML \#0558, Cincinnati, Ohio 452670558. E-mail: branson@aarc.org.

DOI: $10.4187 /$ respcare.08939
}

Stockpile filled the gap as intended, aided in no small part by the resourcefulness of critical care ICU teams.

\section{See the Original Study on Page 366}

This report also includes some real-life experiences from New York City hospitals regarding the use of non-ICU ventilators for these critically ill patients with severe hypoxemia. Of note, the absence of monitoring, particularly graphic displays of airway pressure and flow waveforms, was perceived as operating below the current standard of care in the ICU. Lack of familiarity with devices and the nuances of circuit components and ventilator operation were also identified. Unfortunately, some devices arrived with exhausted battery supplies. $^{\text {? }}$

Finally, the requirements for ventilatory support and the capabilities of devices were compared. ${ }^{7}$ The ventilators recently purchased ranged from full-featured ICU ventilators down to simple portable devices with limited functionality, monitoring, and alarms, the latter being ill-suited for prolonged mechanical ventilation in patients with respiratory failure due to COVID-19. The primary concerns were an inability to deliver the desired modes of ventilation, a fixed inspiratory flow for mandatory breaths (ie, $<40 \mathrm{~L} / \mathrm{min}$ ), a lack of volume and pressure monitoring, limited alarm functions, and an inability to interface with central alarm systems. These factors require respiratory therapists to be available to triage ventilators to match patient needs with device capabilities, as has been described. ${ }^{8}$

In this issue of the Journal, Jonkman and colleagues ${ }^{9}$ describe the bench evaluation of an automatic resuscitator and the laboratory use of this device in a porcine model of severe hypoxemia. They report that the performance of the device is consistent and predictable, with the device responding to decreases in lung compliance with a smaller tidal volume and faster respiratory frequency. This observation is true of all pressure-cycled devices going back to the Bird Mark 7. The authors suggest that this response can alert users to changes in patient condition and allow predictions of tidal volume on the basis of breathing frequency. ${ }^{9}$ The authors note, however, that this would require some additional monitoring equipment to determine respiratory timing. ${ }^{9}$ The evaluation is technically sound as expected from the expertise of 


\section{EDITORIALS}

the authors. Ventilation and oxygenation in a paralyzed, porcine model demonstrated effects comparable to those expected with a standard ventilator, although without the ability to set the breathing frequency, adjust inspired oxygen, manipulate inspiratory time, monitor airway pressure and flow, and trigger an alarm in the case of disconnect or low tidal volume delivery.

The authors conclude that the device is a "low-cost practical rescue solution for providing ventilatory support as a temporary bridge but requires a caregiver at the bedside." This is an important distinction; the designation of an "automatic resuscitator" by the Food and Drug Administration mandates the patient always be attended. To appreciate the changes in breathing frequency associated with a decrease in compliance, a care provider would have to be in direct proximity to the patient. We believe it is important for these findings to be placed in this context. Automatic resuscitators are not low-cost solutions for the needs of patients with respiratory failure due to COVID-19. In the current pandemic, given ICU expansion to accommodate surge, overcapacity, and caregiver shortages, automatic resuscitators and devices with limited function have no utility in stockpiles or caches meant to support patients with ARDS. These should be restricted to short-term, attended use in patients without spontaneous breathing efforts, perhaps during transport to definitive care. The limitations of these devices are significant, including the absence of alarms for failure or disconnect, lack of monitoring capability, pressure-cycled operation, and fixed inspiratory flow resulting in flow starvation in spontaneously breathing patients as demonstrated in the evaluation by Jonkman et al. ${ }^{9}$ PEEP is provided by an external valve, and the only variable set is the pressure cycle threshold. The authors noted that triggering and response is ill suited for patients with any inspiratory effort. ${ }^{9}$

During this pandemic, with a shortage of staff and personal protective equipment, an automatic resuscitator requiring uninterrupted attendance by a caregiver in an overcrowded hospital doesn't represent a solution to ventilator shortages, real or imagined. As the pandemic progresses, staff, personal protective equipment, and oxygen appear to remain the most limited resources. ${ }^{10,11}$ The solutions for mass casualty respiratory failure are complex and multifaceted. The severity of COVID-19 lung injury suggests we should make efforts to have ventilators available that have the performance, monitoring, and alarms commensurate with the severity of the disease. Given our experiences to date, this requires a ventilator designed for acute care that is capable of meeting the demands of patients and providing caregivers with the options, performance characteristics, monitoring, and alarms representing definitive solutions. The device described by
Jonkman fails to meet $75 \%$ of the desired characteristics defined by the Mass Critical Care Task Force. ${ }^{1}$

A constant conundrum with the controversies concerning ventilators for support of COVID-19 is framing of the issue. A shortage of ventilators in a pandemic resulting in mass-casualty respiratory failure cannot be remedied with automatic resuscitators or open-source designs created by well-meaning and talented individuals from other disciplines. Individuals investing their talents and treasure toward rapid ventilator development represent the best in human nature. To our knowledge, however, none of the devices proposed and approved through the Emergency Use Authorization by the Food and Drug Administration have ever been used to support a patient with COVID-19 in the United States or Europe. These imagined solutions have made for feel-good stories during a time when good news has been hard to come by. It is our opinion that one tenet of assistance in this crisis is, if you want to help, "Don't make a ventilator for the first time."

COVID-19 has presented challenges for health care systems around the world. Ventilator shortages, while widely predicted, have not been widespread. With the current vaccine rollout and a predicted end in sight, we should learn from our experiences. Patients with ARDS require ventilators. The use of automatic resuscitators, as advocated by some, ${ }^{12}$ is not a solution to the current or future pandemic. Low cost and ease of use should not be prioritized over function and safety. This is an important message as individuals tasked with purchasing devices in a crisis often have no medical background, and small, light, and inexpensive sounds like a good deal. The authors rightly state that the device is "a temporary bridge, but requires a caregiver at the bedside." Essentially, this statement renders this type of device unusable in the current pandemic. A number of the authors have recently written a compelling expert treatise on lung and diaphragmatic protection ventilation goals and strategies. ${ }^{13} \mathrm{~A}$ ventilator capable of implementing those strategies should be the standard for ventilator performance in COVID-19. Anything less is an imaginary solution.

Richard D Branson University of Cincinnati Department of Surgery Cincinnati, Ohio Editor-in-Chief RESPIRATORY CARE Irving, Texas

Dario Rodriquez Jr University of Cincinnati Department of Surgery Cincinnati, Ohio 


\section{EDITORIALS}

\section{REFERENCES}

1. Einav S, Hick JL, Hanfling D, Christian MD, Dichter JR, Devereaux $\mathrm{AV}$, et al. Surge capacity logistics: care of the critically ill and injured during pandemics and disasters: CHEST consensus statement. Chest 2014; 146(4 Suppl):e17S-e43S.

2. Guérin C, Lévy P. Easier access to mechanical ventilation worldwide: an urgent need for low income countries, especially in face of the growing COVID-19 crisis. Eur Respir J 2020;55(6):2001271.

3. Ranney ML, Griffeth V, Jha AK. Critical supply shortages: the need for ventilators and personal protective equipment during the Covid-19 pandemic. N Engl J Med 2020;382(18):e41.

4. Wells CR, Fitzpatrick MC, Sah P, Shoukat A, Pandey A, El-Sayed $\mathrm{AM}$, et al. Projecting the demand for ventilators at the peak of the COVID-19 outbreak in the USA. Lancet Infect Dis 2020;20(10):11231125 .

5. Rubinson L, Vaughn F, Nelson S, Giordano S, Kallstrom T, Buckley T, et al. Mechanical ventilators in US acute care hospitals. Disaster Med Public Health Prep 2010;4(3):199-206.

6. https://trumpwhitehouse.archives.gov/presidential-actions/memorandumorder-defense-production-act-regarding-purchase-ventilators/. Accessed February 3, 2021.

7. Branson R, Dichter JR, Feldman H, Devereaux A, Dries D, Benditt $\mathrm{J}$, et al. The US strategic national stockpile ventilators in coronavirus disease 2019: a comparison of functionality and analysis regarding the emergency purchase of 200,000 devices. Chest 2020;159(2):634-652.

8. Branson RD, Johannigman JA, Daugherty EL, Rubinson L. Surge capacity mechanical ventilation. Respir Care 2008;53(1):78-88.

9. Jonkman A, Katira B, Annia S, Lu C, Engelberts D, Vieira F, et al. A gas-powered, patient-responsive automatic resuscitator for use in acute respiratory failure: a bench and experimental study. Respir Care 2021;66(3):366-377.

10. Kleinpell R, Ferraro DM, Maves RC, Kane Gill SL, Branson R, Greenberg S, et al. Coronavirus disease 2019 pandemic measures: reports from a national survey of 9,120 ICU clinicians. Crit Care Med 2020;48(10):e846-e855.

11. Lin RG II, Money L, Smith H. Oxygen supply shortages bedevil hospitals already overwhelmed by COVID-19 patients. Los Angeles Times: December 29, 2020. Chest 2020. https://www.latimes.com/ california/story/2020-12-29/oxygen-supply-shortages-bedevil-hospitalsalready-overwhelmed-by-covid-19-patients. Accessed February 9, 2021.

12. Dar M, Swamy L, Gavin D, Theodore A. Mechanical ventilation supply and options for the COVID-19 pandemic: Leveraging all available resources for a limited resource in a crisis. Ann Am Thorac Soc 2020 [Epub ahead of print] doi: 10.1513/AnnalsATS.202004-317CME.

13. Goligher EC, Dres M, Patel BK, Sahetya SK, Beitler JR, Telias I, et al. Lung- and diaphragm-protective ventilation. Am J Respir Crit Care Med 2020;202(7):950-961. 